\section{Pathogenic conjunctival bacteria associated with systemic co-morbidities of patients undergoing cataract surgery}

M-E Fernández-Rubio1, T Cuesta-Rodríguez², J-L Urcelay-Segura ${ }^{2}$ and C Cortés-Valdés ${ }^{2}$

\begin{abstract}
Purpose To identify the risk of patients undergoing cataract surgery of having pathogenic conjunctival bacteria associated with their systemic co-morbidities.

Methods Retrospective study of consecutive patients undergoing their first cataract operation from July 2005 to April 2010. Their preoperative conjunctival bacteria were cultured, identified, and classified in bacterial groups. Their co-morbidities were defined from their clinical data and the answers to systematic questions asked in the anaesthetic evaluation. The Microsoft Access databases of the two data sets were merged for carrying out the statistical analysis. Univariate association of each bacterial group with each co-morbidity was studied by using $\chi^{2}$-test for categorical data and Student's $t$-test for continuous variables. Also, logistic regression models were used adjusting for age and sex. SPSS statistic programme, version 18 was used for all these analyses. Endophthalmitis cases in this surgical series were searched. Results In the 8333 selected patients, age was associated with increased conjunctival bacteria in all groups except for Streptococcus pneumoniae and Propionibacteriae. However, male sex was associated with these two groups and also with coagulase-negative Staphylococci, Corynebacterium xerosis, Staphylococcus aureus, and Gram-negative rods. After adjusting for age and sex, S. aureus was associated with diabetes, lung diseases, and renal and heart insufficiency; Gram-negative rods with smoking habit; Enterococci with diabetes; Streptococcus pneumoniae with kyphoscoliosis; and other
\end{abstract}

Streptococci with diabetes and handicapped patients.

Conclusion The more pathogenic conjunctival bacteria were more likely associated with patients' co-morbidities, such as diabetes, lung diseases, renal and heart insufficiency, kyphoscoliosis, and smoking habit, than the less pathogenic ones.

Eye (2013) 27, 915-923; doi:10.1038/eye.2013.103; published online 24 May 2013

Keywords: pathogenic conjunctival bacteria; preoperative conjunctival bacteria; postoperative endophthalmitis; systemic co-morbidities; co-morbidities of patients with cataract; cataract surgery prophylaxis

\section{Introduction}

A higher incidence of postoperative endophthalmitis (PE) after cataract surgery has repeatedly been associated with advanced age and male sex of the patients, even after using the best current surgical prophylaxes. ${ }^{1-10}$ Apart from the risk due to surgical complication such as the capsular posterior rupture, $, 4,7,11,12$ other PE risks have occasionally been described, for instance diabetes ${ }^{13,14}$ and immunosuppression. ${ }^{15}$ The magnitude of the men as a group at risk, the imprecision of the age factor, the low incidence of $\mathrm{PE}$, and our previous finding of a higher prevalence of certain pathogenic conjunctival bacteria in diabetics undergoing cataract operation ${ }^{16}$ suggest the hypothesis of patients having other concomitant characteristics partially responsible for the increased PE incidence of men and older patients, which could imply more reduced subgroups of patients at risk.
${ }^{1}$ Ophthalmic Institute Laboratory, Department of Ophthalmology, "Gregorio Marañón" University General Hospital, Madrid, Spain

${ }^{2}$ Department of Ophthalmology, "Gregorio Marañón" University General Hospital, Madrid, Spain

Correspondence: M-E Fernández-Rubio, c/ Vizconde de los Asilos, 12, $2^{\circ}$ B, Madrid 28027, Spain

Tel: + 3491586 7326; Fax: + 34915867330 .

E-mail: mfernandezr. hgugm@salud.madrid.org

Received: 13 August 2012 Accepted in revised form: 28 April 2013

Published online: 24 May 2013 
In the Endophthalmitis Vitrectomy Study (EVS), ${ }^{17}$ a poorer visual outcome was clearly attributed to the bacteria different from coagulase-negative Staphylococci (CNS) isolated in their PE cases. Since then, the bacterial endophthalmitis pathogenesis has been carefully studied and reviewed, ${ }^{18,19}$ emphasising the pathogenic power of certain bacteria such as Staphylococcus aureus,

Streptococcus species, Enterococci, Bacillus spp and most Gram-negative rods in the postoperative cases. The devastating effect of these bacteria was also shown after the EVS in several studies., ${ }^{40-25}$ Taking into account the role of the conjunctival flora as the main source of bacterial contamination during the intraocular surgery, 26 what is remarkable is the low prevalence of these pathogenic bacteria on the conjunctiva of patients operated on for cataract in all the published studies. ${ }^{27-30}$ However, very little is known about whether the clinical characteristics of this small number of patients with pathogenic bacteria colonising their conjunctivas are different. ${ }^{16,31-33}$ Today, the available data of the Human Microbiome Project reveals the possibility of determining differences between the microbiomes of healthy and unhealthy people. ${ }^{34}$ This fact opens a new horizon in the management of infectious diseases. In this way, a relation between the pathogenic conjunctival bacterial colonisation and the clinical characteristics of patients undergoing cataract surgery could be useful for easily identifying those with a higher risk of pathogenic bacterial contamination during the cataract operation, and consequently counselling these patients about their potential risk of a poorer visual outcome (caused by certain PE) and owing to their health status.

The aim of the present study is to investigate the association of pathogenic and less pathogenic conjunctival bacterial colonisation with a wide range of patients' co-morbidities in a big sample of patients undergoing their first cataract operation, independently of the factors of age and sex.

\section{Materials and methods}

\section{Study design}

A retrospective cross-sectional study of consecutive patients who underwent their first planned cataract operation in a teaching tertiary hospital from July 2005 to April 2010. Every patient awaiting their first cataract operation had, in this study, a preoperative examination (established by a protocol) consisting of: a basic clinical analysis, an electrocardiogram (ECG), a thorax $X$ ray, a conjunctival bacterial culture, and a clinical evaluation for anaesthetic and surgical purposes. During this evaluation, the patients were asked about their current medication and about a fixed set of diseases previously diagnosed, and the answers were systematically recorded in a Microsoft Access database, together with the interview date, the surgery indicated, the medical record numbers, the demographic data of the patients, and the results of the preoperative tests. From this database, the co-morbidity variables were defined as it was summarised in Supplementary Table 1. The conjunctival bacteria isolated in each of the patients were prospectively recorded in the laboratory database, which also contains the medical record numbers and demographic data of the patients, and the origin and collecting date of the samples among other data. Bacteria were grouped as in order to obtain a number of samples as big as possible for carrying out statistical comparisons, and paying attention to their above described pathogenic power in PE cases ${ }^{17-25}$ (S. aureus, Streptococcus species, Enterococci, Bacillus spp, and most Gram-negative rods).

The patients were selected, by means of the Microsoft Office Access 2003 utilities, from the records of the laboratory database from 11 July 2005 to 1 April 2010, and from the records of the anaesthetic and surgical purposes database from 11 January 2005 to 30 April 2010, to ensure that each culture corresponds to a first cataract operation, (if a second cataract operation on a patient is performed within 6 months of his first, only the conjunctival bacterial culture is carried out). The following exclusion criteria were applied: (1) The laboratory records of any subsequent cataract operations after the first study record were excluded, in order to avoid the effect of a previous antibiotic prophylaxis on the conjunctival bacteria. (2) Cataract operations combined with other surgical procedures were excluded.

The laboratory database was linked to the anaesthetic and surgical purposes database, by means of the Microsoft Office Excel 2003 utilities. Any discrepancy in the linking process was resolved by checking in the hospital records computerised system and in the medical records of the patients. The records of the merged database were de-identified before performing the statistical analysis. This research adheres to the tenets of the Declaration of Helsinki. Our hospital ethics committee approved the publication of this study.

\section{Microbiological method}

The specimens' collection and the culture technique are described elsewhere. ${ }^{16,35}$ Patients were instructed for not washing their eyes and not using any kind of ocular drops in the morning before the specimens were collected; and also not using antibiotics during the previous $48 \mathrm{~h}$. The identification and antibioticsusceptibility test of non-exigent growing bacteria was performed as follows: panel PC23 was used for Enterococci, all Staphylococci with positive mannitol test 
and those Staphylococci mannitol negative, when more than five colony-forming units (CFU) per microlitre, were isolated; panels PC38 and PUC37 were used for Gramnegative rods All these panels (from Dade Behring, Siemens Healthcare Diagnostics, Barcelona, Spain) were automatically read and recorded in the AutoScan 4 microbiological system (Siemens Healthcare Diagnostics). For more exigent growing bacteria, the identification of Haemophilus, Neisseria, and Moraxella was carried out with the HNID Dade Behring panel. Streptococci, Propionibacteria, Corynebacteria, and other Gram-positive rods were identified by their growing characteristics, and their macroscopic and microscopic morphology; $S$. pneumoniae was differentiated by the optochin disc. The antibiotic-susceptibility tests (with agar diffusion technique) were carried out for every bacteria considered pathogenic and for those less pathogenic when their colony count was higher than five CFU, except for Corynebacterium xerosis and Propionibacterium spp, which were never tested for antibiotic susceptibility.

\section{Surgical prophylaxis}

All patients received Oftalmotrim eye-drops (Alcon Laboratory, Barcelona, Spain), every $3 \mathrm{~h}$ (within 9 and $24 \mathrm{~h}$ ), for five days before the surgery, except those patients having pathogenic conjunctival bacteria or a high count of non-pathogenic bacteria resistant to the Oftalmotrim antibiotics, (polymyxin B and trimethoprim). These ones received another eye-drop antibiotic according to their susceptibility tests. When Enterococci or Gram-negative rods (except Haemophilus spp) were isolated in a patient, his cataract operation was delayed until a non-pathogen conjunctival bacterial pattern was obtained; otherwise, an antibiotic oral prophylaxis was used. For every patient of the study, $10 \mathrm{~min}$ before of the operation, povidone-iodine $5 \%$ solution was instilled into the conjunctival sac and the surrounding ocular area was also scrubbed with the same solution. The postoperative prophylaxis was chosen by the surgeon. After March 2006, according to the ECSRS study guidelines, ${ }^{5}$ intracameral cefuroxime or vancomycin injections were progressively used over the study period, in addition to the previous prophylactic measures.

To evaluate the efficacy of our prophylaxis, we retrospectively searched the PE cases occurred in these 8333 surgeries by means of the hospital computerised system containing the International Classification of Diseases, ninth revision ${ }^{36}$ codes. For endophthalmitis: 360.00 (non-specified purulent endophthalmitis); 360.01 (acute endophthalmitis); 360.02 (panendophthalmitis); 360.03 (chronic endophthalmitis); and 360.19 (other endophthalmitis). In order to separate the PE occurred in surgeries during the phacoemulsification technique (PHACO) from those during the intracapsular cataract extraction (ICCE) and the extracapsular cataract extraction (ECCE), we also searched for the codes 13.19 (ICCE) and 13.59 (ECCE).

\section{Statistical analysis}

Descriptive analyses were performed for all variables. The percentages of each co-morbidity in men and women were compared. The univariate association of the prevalence of each bacterial group with each of the clinical characteristics of the patients defined as variables was initially examined using $\chi^{2}$-test for categorical variables and Student's $t$-test for continuous variables. The logistic regression models were used to study the association of the conjunctival bacterial groups and different co-morbidities, which were expressed as odds ratios and 95\% confidence intervals. All analyses were performed controlling the effect of age and sex, as these two variables have been shown to influence the prevalence of the conjunctival bacteria on patients undergoing cataract surgery in a previous study. ${ }^{28}$ These analyses were performed using IBM SPSS STATISTICS (version 18; IBM Corporation, Armonk, NY, USA). For all the analyses, $P<0.05$ was considered statistically significant.

\section{Results}

There were 8333 patients operated on for their first cataract over the 5-year period, aged from 18 to 98 , mean age 73.66 and SD $9.24 ; 57.4 \%$ of the patients were older than 73 years. The mean age of the 3687 men $(44.2 \%)$ was 72.65 , SD 9.79; the mean age of the 4646 women being 74.47 , SD 8.70. The age of the women was higher than that of the men $(P<0.001)$. The prevalence of the defined patients' co-morbidities is given in Table 1, beside the mean age of each co-morbidity group. The prevalence of the variables diabetics, lung diseases, smokers plus ex-smokers, renal insufficiency, ischaemic cardiopathies, and any ECG abnormality was statistically higher in men; but aortic atheroma and kiphoscoliosis were more prevalent in women, these two groups of patients having the highest mean age (above 78 years). The prevalence of the grouped conjunctival bacteria is shown in Table 2. In all bacterial groups except for S. pneumoniae, Enterococci, C. xerosis, and Propionibacterium spp, a patient could be colonised by more than one species of the same group, this being more frequent in the CNS group.

In the univariate analysis of the association study, the groups of Haemophilus spp and other Gram-positive rods were not associated with none of the co-morbidities; the 
Table 1 Prevalence of co-morbidities in our patients undergoing cataract surgery: prevalence comparison in men and women

\begin{tabular}{|c|c|c|c|c|c|c|c|c|c|}
\hline \multirow[t]{2}{*}{ Co-morbidities } & \multicolumn{4}{|c|}{8333 patients } & \multicolumn{2}{|c|}{3687 men } & \multicolumn{2}{|c|}{4646 women } & \multirow{2}{*}{$\frac{\% \text { Comparison }}{\text { P-value }}$} \\
\hline & Number & $\%$ & $(95 \% C I)$ & Mean age (SD) & Number & $\%$ & Number & $\%$ & \\
\hline Diabetes & 2231 & 26.8 & $(25.8-27.7)$ & $73.82(08.12)$ & 1035 & 28.1 & 1196 & 25.7 & 0.018 \\
\hline Lung diseases & 1294 & 15.5 & $(14.7-16.3)$ & $74.65(08.67)$ & 762 & 20.7 & 532 & 11.5 & $<0.001$ \\
\hline Smokers + ex-smokers & 1844 & 22.1 & $(21.2-23.0)$ & $70.44(10.63)$ & 1614 & 43.8 & 230 & 5.0 & $<0.001$ \\
\hline Renal insufficiency & 737 & 8.8 & $(08.2-09.5)$ & $77.19(08.25)$ & 481 & 13.1 & 256 & 5.5 & $<0.001$ \\
\hline Liver diseases & 590 & 7.1 & $(06.5-07.6)$ & $70.91(10.29)$ & 304 & 8.3 & 286 & 6.2 & $<0.001$ \\
\hline Immunosuppression & 462 & 5.5 & $(05.1-06.0)$ & $71.74(10.03)$ & 200 & 5.4 & 262 & 5.6 & 0.706 \\
\hline Taking $\alpha$-AR blockers & 1024 & 12.3 & $(11.6-13.0)$ & 75.19 (07.47) & 817 & 22.2 & 207 & 4.5 & $<0.001$ \\
\hline High blood pressure & 5407 & 64.9 & $(63.9-65.9)$ & $75.34(07.62)$ & 2246 & 60.9 & 3161 & 68.0 & $<0.001$ \\
\hline Any ECG abnormality & 2760 & 33.1 & $(32.1-34.1)$ & $76.32(07.38)$ & 1459 & 39.6 & 1301 & 28.0 & $<0.001$ \\
\hline Ischaemic cardiopathies & 1109 & 13.3 & $(12.6-14.0)$ & $74.29(07.55)$ & 669 & 18.2 & 440 & 9.5 & $<0.001$ \\
\hline Heart insufficiency & 794 & 9.5 & $(08.9-10.2)$ & $76.26(07.52)$ & 345 & 9.4 & 449 & 9.7 & 0.662 \\
\hline Aortic atheroma & 1002 & 12.0 & $(11.3-12.7)$ & $78.16(06.63)$ & 355 & 9.6 & 647 & 13.9 & $<0.001$ \\
\hline Kiphoscoliosis & 157 & 1.9 & $(01.6-02.2)$ & $78.45(07.29)$ & 23 & 0.6 & 134 & 2.9 & $<0.001$ \\
\hline Handicapped patients & 418 & 5.0 & $(04.5-05.5)$ & $76.08(08.94)$ & 178 & 4.8 & 240 & 5.2 & 0.515 \\
\hline
\end{tabular}

Abbreviation: $\alpha$-AR, $\alpha$-adrenoreceptors; CI, Confidence intervals; ECG, electrocardiogram; SD, Standard deviation.

Bold printed $\%$ numbers indicate the sex percentage values outside of the CI percentage in each group.

variables liver diseases and immunosuppression were not associated with any of the bacterial groups. The results of the logistic regression for the remaining variables are shown in Table 3 (associations of the pathogenic bacteria) and Table 4 (associations of the non-pathogenic bacteria). Age was associated with most conjunctival bacterial groups except for S. pneumoniae and Propionibacterium spp, which were increased in male sex. In addition, male sex was associated with S. aureus, Gram-negative rods, CNS, and C. xerosis. After adjusting for age and sex, a higher prevalence of $S$. aureus is associated with diabetes, lung diseases, renal and heart insufficiency; Gram-negative rods with smokers plus exsmokers; S. pneumoniae with kyphoscoliosis; Enterococci with diabetes; other Streptococci with diabetes and handicapped patients (Table 3 ). There were very few co-morbidities associated with less pathogenic bacteria (Table 4).

In the present study, there were four PE cases, two in 2005 and the other two in 2006 (Table 5). The overall PE incidence was $0.048 \%$ including the surgeries with planned ECCE and those PHACO reconverted to ECCE because of having intraoperative complications. For PHACO surgeries the PE incidence was $0.012 \%$. The cultures of intraocular samples of the PE cases were not available.

\section{Discussion}

Our sample of patients has the same distribution of age and sex as most of the series of patients operated on for cataract. ${ }^{1-9,27-29,37,38}$ However, the prevalence of patients' systemic co-morbidities, without grouping them as a health status index, is rarely described in such series. ${ }^{30,37,38}$ These co-morbidities could have been overrepresented among our patients (Table 1) because of our hospital being a tertiary one, which seems to be the case in the Auckland cataract study ${ }^{38}$ too; in fact, in population cataract studies ${ }^{2}$ or in those studies involving several settings ${ }^{37,39}$ a lower rate of some systemic comorbidities was obtained. Our higher prevalence of systemic co-morbidities in men (Table 1) could introduce some bias in our results. However, our proportion of comorbidities in both sexes is similar to that found in old people in the general population in recent studies, ${ }^{40,41}$ which indicates that men operated on for cataract in the last decades could have similar co-morbidity rate. For example, our different prevalence of smokers in both sexes is also shown in another coetaneous study of patients with cataract. ${ }^{42}$

To our knowledge, the present study contains the biggest cohort of consecutive patients undergoing their first cataract surgery in which a wide range of individual co-morbidities were associated with the prevalence of their conjunctival bacteria. Previously, Fahmi et al ${ }^{27}$ found a correlation between male sex and the prevalence of Corynebacteria and Gram-negative rods; other small studies associated the conjunctival bacteria with a particular co-morbidity such as patients taking immunosuppressive drugs ${ }^{31}$ or those having diabetes; ${ }^{32,33}$ Miño de Kaspar et $a l^{29}$ found that advanced age and patients grouped for having diabetes, immunosuppression, autoimmune conditions, and asthma had a higher rate of positive conjunctival cultures than the control group, but they did not find any gender association. Recently, ${ }^{30}$ with fewer patients, no association was found between conjunctival bacterial 
Table 2 Prevalence of each bacterial group in 8333 patients undergoing cataract surgery

\begin{tabular}{|c|c|c|c|c|}
\hline \multirow{2}{*}{$\begin{array}{l}\text { Groups of bacteria } \\
\text { Staphylococcus aureus }\end{array}$} & \multicolumn{4}{|c|}{ Species Species \% Patients ${ }^{\text {a }}$ Patients \% } \\
\hline & 784 & 9.41 & 775 & 9.30 \\
\hline Achromobacter xylosoxidans & 1 & 0.01 & & \\
\hline Acinetobacter lwoffii & 9 & 0.11 & & \\
\hline Aeromonas hydrophila & 1 & $0, .01$ & & \\
\hline Bordetella bronchiseptica & 1 & $0, .01$ & & \\
\hline Burkholderia cepacia & 2 & 0.02 & & \\
\hline Citrobacter species & 20 & 0.24 & & \\
\hline Empedobacter brevis & 1 & 0.01 & & \\
\hline Enterobacter species & 31 & 0.37 & & \\
\hline Escherichia species & 11 & 0.13 & & \\
\hline Hafnia alvei & 1 & 0.01 & & \\
\hline Klebsiella species & 23 & 0.28 & & \\
\hline Morganella morganii & 55 & 0.66 & & \\
\hline Proteus species & 134 & 1.61 & & \\
\hline Providencia rettgeri & 2 & 0.02 & & \\
\hline Pseudomonas species & 35 & 0.42 & & \\
\hline Serratia species & 16 & 0.19 & & \\
\hline Sphingobacterium multivorum & 1 & 0.01 & & \\
\hline Stenotrophomonas maltophilia & 6 & 0.07 & & \\
\hline Other non-fermentative & 49 & 0.59 & & \\
\hline \multicolumn{5}{|l|}{ Gram-negative rods } \\
\hline Gram-negative rods (total) & 399 & 4.79 & 378 & 4.54 \\
\hline Streptococcus pneumoniae & 229 & 2.75 & 229 & 2.75 \\
\hline Enterococci & 175 & 2.10 & 175 & 2.10 \\
\hline Other Streptococci & 1353 & 16.24 & 1312 & 15.74 \\
\hline Gram-negative diplococci & 308 & 3.70 & 302 & 3.62 \\
\hline Haemophilus species & 266 & 3.19 & 265 & 3.18 \\
\hline Staphylococcus auricularis & 12 & 0.14 & & \\
\hline Staphylococcus capitis & 110 & 1.32 & & \\
\hline Staphylococcus cohnii & 6 & 0.07 & & \\
\hline Staphylococcus epidermidis & 4614 & 55.37 & & \\
\hline Staphylococcus haemolyticus & 31 & 0.37 & & \\
\hline Staphylococcus hominis & 53 & 0.64 & & \\
\hline Staphylococcus intermedius & 12 & 0.14 & & \\
\hline Staphylococcus lugdunensis & 121 & 1.45 & & \\
\hline Staphylococcus saprophyticus & 7 & 0.08 & & \\
\hline Staphylococcus schleiferi & 12 & 0.14 & & \\
\hline Staphylococcus simulans & 22 & 0.26 & & \\
\hline Staphylococcus warneri & 53 & 0.64 & & \\
\hline Staphylococcus xylosus & 4 & 0.05 & & \\
\hline CNS mannitol test-negative ${ }^{\mathrm{b}}$ & 2478 & 29.74 & & \\
\hline Coagulase-negative & 7535 & 90.42 & 6433 & 77.20 \\
\hline \multicolumn{5}{|l|}{ Staphylococci (total) } \\
\hline Corynebacterium xerosis & 3964 & 47.57 & 3964 & 47.57 \\
\hline Other diphtheroids & 908 & 10.90 & 898 & 10.78 \\
\hline Propionibacterium species & 2012 & 24.14 & 2012 & 24.14 \\
\hline Other Gram-positive rods & 99 & 1.19 & 99 & 1.19 \\
\hline
\end{tabular}

a Some patients had some bacterial species belonging to the same bacterial group. Bold-typed lines are the bacteria grouped for analysis.

${ }^{\mathrm{b}}$ Without species identification because of their colony count being $<5$ colony-forming units.

prevalence and diabetes, steroid therapy, dialysis and allergic conjunctivitis, but an association was found with age above 60. Most of these positive associations are in agreement with our results (Tables 3 and 4), probably because of our higher number of patients and our larger variety of isolated bacteria ${ }^{43}$ (Table 2). In a previous study, ${ }^{28}$ we also found an increased conjunctival bacteria prevalence in old people and male sex, but the current finding of the higher co-morbidities prevalent in males adds a new piece of information to understand why men have a higher risk of PE. ${ }^{1,4-10}$ Diabetes, lung diseases, smokers plus ex-smokers, renal insufficiency, and ischaemic cardiopathies are more prevalent in men (Table 1).

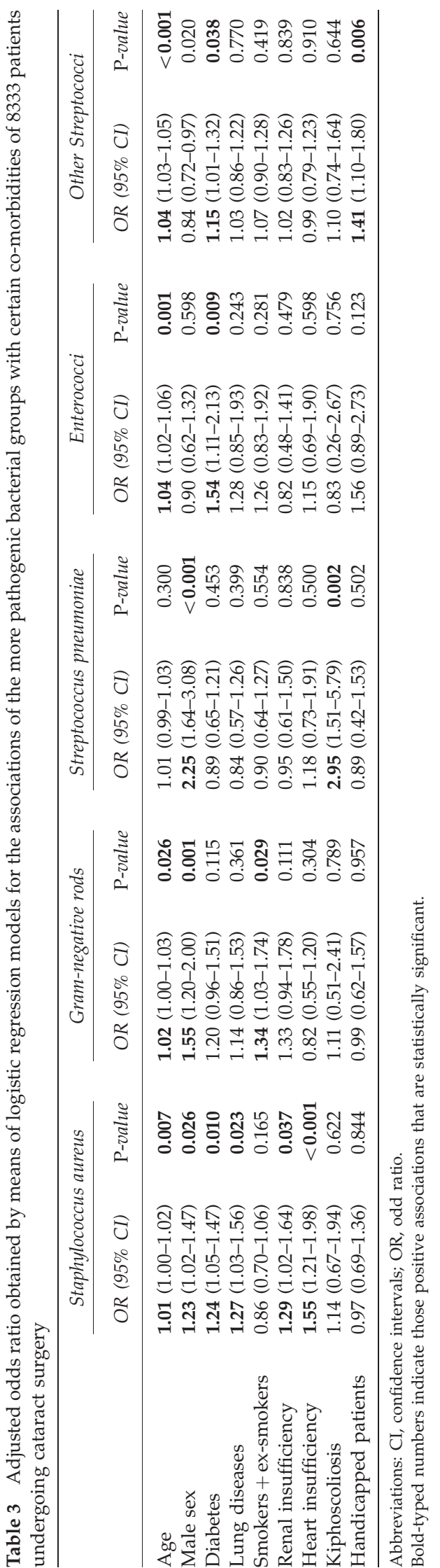




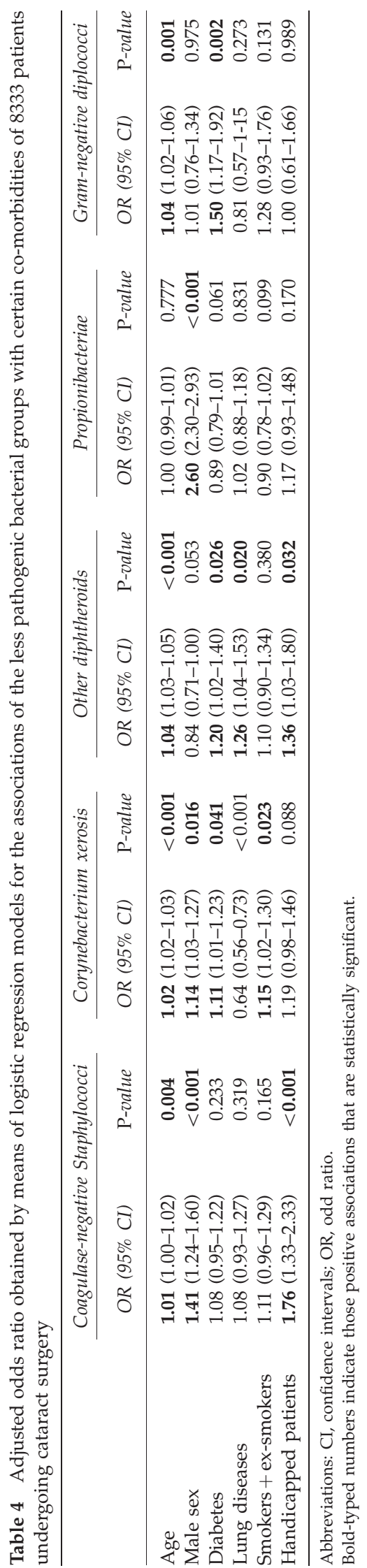

Table 5 Annual cases of all cataract surgeries, ECCE, PHACO, ICCE, and their PE cases

\begin{tabular}{|c|c|c|c|c|c|c|c|}
\hline \multirow[t]{2}{*}{ Annual periods } & \multicolumn{2}{|c|}{$\begin{array}{l}\text { All cataract } \\
\text { surgeries }\end{array}$} & \multicolumn{2}{|c|}{ ECCE surgeries } & \multicolumn{2}{|c|}{$\begin{array}{l}\text { PHACO } \\
\text { surgeries }\end{array}$} & \multirow{2}{*}{$\begin{array}{l}\text { ICCE } \\
\begin{array}{l}\text { ICCE } \\
\text { cases }\end{array}\end{array}$} \\
\hline & Cases & $\begin{array}{c}\text { PE cases } \\
(\%)\end{array}$ & $\begin{array}{l}\text { ECCE } \\
\text { cases } \\
(\%)^{\mathrm{a}}\end{array}$ & $\begin{array}{c}P E \\
\text { cases } \\
(\%)\end{array}$ & Cases & $\begin{array}{c}P E \text { cases } \\
(\%)\end{array}$ & \\
\hline July 2005-2006 & 1901 & $4(0.210)$ & $40(2.10)$ & $3(7.50)$ & 1859 & $1(0.054)$ & 2 \\
\hline July 2006-2007 & 1814 & & $26(1.43)$ & & 1788 & & 1 \\
\hline July 2007-2008 & 1621 & & $19(1.17)$ & & 1602 & & \\
\hline July 2008-2009 & 1841 & & $10(0.54)$ & & 1831 & & \\
\hline July $2009-2010^{\mathrm{b}}$ & 1156 & & $3(0.26)$ & & 1153 & & \\
\hline Total & 8333 & $4(0.048)$ & 98 & $3(3.06)$ & 8232 & $1(0.012)$ & 3 \\
\hline
\end{tabular}

Abbreviations: ECCE, extracapsular cataract extraction; ICCE, intracapsular cataract extraction; PE, postoperative endophthalmitis; PHACO, phacoemulsification technique.

a Percentage of the annual surgeries.

${ }^{\mathrm{b}}$ All periods finished on 10 July except the last one, on 31 March.

After adjusting for age and sex, there are still some pathogenic bacterial groups associated with four of these co-morbidities (Table 3). The association of male sex with Propionibacterium spp (not cultured in our previous series of patients ${ }^{28}$ ) is a new finding of this study (Table 4). These facts suggest that part of the increased conjunctival bacteria of men operated on during this study period could be attributed to their lifestyle. The association of diabetes with Enterococci, S. aureus, other Streptococci and Gram-negative diplococci is in line with the conjunctival bacterial pattern described previously for diabetic people, ${ }^{16}$ where the bacterial prevalence in renal insufficiency was also shown. However, the following associations of pathogenic bacteria are now identified for the first time: S. aureus with lung diseases and heart insufficiency; Gram-negative rods with smokers plus ex-smokers; S. pneumoniae with kyphoscoliosis; and other Streptococci with handicapped patients (Table 3).

We hypothesised that some blood factors could enhance the growing of certain bacteria in patients having certain co-morbidities. For instance, bacteria that strongly ferment glucose (most Staphylococci, Enterococci, most Streptococci except for S. pneumoniae and most Enterobacteriaceae) in diabetics; bacteria that grow with a lower oxygen concentration (Propionibacteriae) in smokers; bacteria that need lipid supplementation for growing (C. xerosis and other diphtheroids) in hyperlipidaemic old patients (data not provide in this study). However, we cannot suggest possible hypothesis for all the found associations. In any case, similar studies in other settings are needed to reinforce the consistence of these associations, and afterwards investigate the causes of them.

Our surgical prophylaxis was as effective as those used in current studies that obtained the lowest incidence of PE. 4,5,10,44 However, our prophylaxis has been changing over the study period and the PE 
incidence too; the PE cases were concentrated in the first year of the study period, with no cases in the following years. In our opinion, several factors could be responsible for our PE incidence decrease: the gradual increase in the use of cefuroxime after March 2006; the technological improvement of the phacoemulsification machines; the introduction of tools for better-managed surgical complications; the gradual decrease of surgeries that were performed with the ECCE technique year after year (Table 5); and the annual differences of the conjunctival bacterial prevalence. The effect of these factors are documented in several studies, ${ }^{4,5,9,10,45-47}$ except the last factor, whose possible influence is shown in this study for the first time. In particular, the S. pneumoniae prevalence decreased significantly from $5.89 \%$ in the first year of the study period to $1.38 \%$ in the last year; this change of prevalence could be due to the old people vaccination campaign that took place in our country over the study period (Supplementary Table 2). Owing to our low incidence of $\mathrm{PE}$, the number of cataract operations of our study is very small for drawing conclusions on the efficacy of the different steps of our prophylaxis; however, in this study there were a big PE incidence reduction $(0.048 \%)$ compared with the PE incidence of our series of patients operated on in the period 1994-1996 $(0.406 \%) .{ }^{47,48}$ During the mid-nineties, the povidoneiodine solution was not used systematically as it was used in the present study; the ECCE technique was still predominant, and the intracameral cefuroxime and the $S$. pneumoniae vaccination were not used at all.

Also, because of our insufficient number of cataract operations and PE cases, we cannot demonstrate the association of the PE risk with the patient co-morbidities. For similar reasons, because of the current efficacy of the prophylaxes, ${ }^{4,5,10}$ the ascertaining of the value of the systemic co-morbidities as potential indicator of the PE risk is restricted to those PE cases caused by pathogenic bacteria highly resistant to the prophylaxes. For instance, after using topical chlorhexidine solution and intracameral cefuroxime, the PE incidence caused by Enterococci was relatively high (23\% of their PE cases) in Sweden, ${ }^{4}$ probably owing to the antimicrobial resistance of these bacteria (according to our antibiotic resistance pattern $^{35}$ ). In the present study, the conjunctival prevalence of Enterococci was $2.1 \%$, and this bacterial colonisation was associated with diabetes and advanced age. The potential risk of intraocular contamination by Enterococci during the cataract surgery of our patients was increased 1.6 and 2.5 times in those over 85 and 90 years, respectively, in spite of having a decrease in the diabetes prevalence above the age of 85 (see the prevalence of Enterococci in groups of age in Supplementary Table 3 . We had no PE cases while we were using intracameral cefuroxime, (similar to that used in the Swedish study ${ }^{4}$ ); but in addition, we had used topical antibiotics, povidone-iodine instead of chlorhexidine and we knew in advance the susceptibility of Enterococci to the antibiotics. These facts suggest that PE incidence due to Enterococci could be reduced by modifying the prophylaxis of diabetics and patients older than 85 years.

There are some possible weaknesses in our study. First, the prevalence of co-morbidities could be under-reported because some patients did not know what diseases they had when they passed the clinical evaluation for anaesthetic purposes; this possible weakness would make the associations of the affected co-morbidities stronger, as that means that we have counted false negative among those patients without reporting co-morbidity. Second, $2.41 \%$ of the patients admitted in the evaluation that they did not remember the whole medication that they were taking; this lack of information could affect the reliability of variables defined by means of the medication such as taking $\alpha$-adrenoreceptors blockers, immunosuppression, and high blood pressure. Third, another limitation comes from the fact of grouping bacteria. For instance, among the Gram-negative rods, we found that Klebsiella spp is more prevalent in diabetics than in non-diabetics. ${ }^{16}$ However, the design of the present study does not allow the analysis of the Gram-negative rods group in more detail. Finally, using a microbiological culture method for isolating the conjunctival bacteria could be a limitation compared with using $16 \mathrm{~S}$ rDNA sequencing-based detection and identification, because of the wider spectrum of ocular surface bacteria described recently in a pilot study of four patients. ${ }^{49}$ However, in another study using both methods, conventional culture and eubacterial PCR (16S rDNA sequences compared with those available in the GenBank, EMBL), for identifying bacteria in $100 \mathrm{PE}$ cases, the rate of positive identification was not statistically different. ${ }^{50}$ In fact, the current cataract surgery prophylaxes based on the antibiotic susceptibility of cultured bacteria are efficacious. ${ }^{4,5,10,44,47}$

In conclusion, certain systemic co-morbidities of the patients undergoing cataract surgery could alert ophthalmic surgeons to the risk of these patients for having pathogenic conjunctival bacteria and could help to control the suitability of the surgical prophylaxis in use. The groups of patients most affected are diabetics, those suffering from lung diseases, renal or heart insufficiency and kyphoscoliosis, smokers and ex-smokers, and the handicapped, independently of the increase of age and male sex, which are also risk factors for having a higher conjunctival bacterial prevalence. 


\section{Summary}

\section{What was known before}

- A higher conjunctival bacterial prevalence is associated with advanced age, male sex, diabetes, and renal insufficiency in patients awaiting cataract surgery.

- The visual outcome of PE cases caused by pathogenic bacteria is worse than in those endophthalmitis caused by common conjunctival colonisers such as coagulasenegative Staphylococci.

\section{What this study adds}

- Men had a higher prevalence of co-morbidities than women and had also a higher prevalence of conjunctival bacteria associated with their co-morbidities.

- The increased prevalence of the pathogenic conjunctival bacteria is associated with certain systemic co-morbidities of patients needing cataract operation. However, these associations were less frequently found with non-pathogenic bacteria.

\section{Conflict of interest}

The authors declare no conflict of interest.

\section{Acknowledgements}

The authors thank José Antonio Tintó, MD, who collected part of the data; José Ma Bellón, for helping with statistical calculations and David Frost for his assistance with the English translation.

\section{References}

1 Norregaard JC, Thoning H, Bernth-Petersen P, Andersen TF, Javitt JC, Anderson GF. Risk of endophthalmitis after cataract extraction: results from the international cataract surgery outcomes study. Br J Ophthalmol 1997; 81: 102-106.

2 Li J, Morlet N, Ng JQ, Semmens JB, Knuiman MW. Team EPSWA. Significant nonsurgical risk factors for endophthalmitis after cataract surgery: EPSWA fourth report. Invest Ophthalmol Vis Sci 2004; 45: 1321-1328.

3 West ES, Behrens A, McDonnell PJ, Tielsch JM, Schein OD. The incidence of endophthalmitis after cataract surgery among the U.S. Medicare population increased between 1994 and 2001. Ophthalmology 2005; 112: 1388-1394.

4 Lundstrom M, Wejde G, Stenevi U, Thorburn W, Montan P. Endophthalmitis after cataract surgery: a nationwide prospective study evaluating incidence in relation to incision type and location. Ophthalmology 2007; 114: 866-870.

5 ESCRS Endophthalmitis Study Group. Prophylaxis of postoperative endophthalmitis following cataract surgery: results of the ESCRS multicenter study and identification of risk factors. J Cataract Refract Surg 2007; 33: 978-988.

6 Cedrone C, Ricci F, Regine F, Cerulli A, Palma S, Culasso F. Nationwide incidence of endophthalmitis among the general population and the subjects at risk of endophthalmitis in Italy. Ophthalmic Epidemiol 2008; 15: 366-371.

7 Hacth WV, Cernat G, Wong D, Devenyi R, Bell CM. Risk factors for acute endophthalmitis after cataract surgery: a population-based study. Ophthalmology 2009; 116: 425-430.

8 Freeman EE, Roy-Gagnon M-H, Fortin E, Gauthier D, Popescu M, Boisjoly H. Rate of endophthalmitis after cataract surgery in Quebec, Canada, 1996-2005. Arch Ophthalmol 2010; 128: 230-234.

9 Keay L, Gower EW, Cassard SD, Tielsch JM, Schein OD. Postcataract surgery endophthalmitis in the United States. analysis of the complete 2003 to 2004 medicare database of cataract surgeries. Ophthalmology 2012; 119: 914-922.

10 Tan CS, Wong HK, Yang FP. Epidemiology of postoperative endophthalmitis in an Asian population: 11-year incidence and effect of intracameral antibiotic agents. J Cataract Refract Surg 2012; 38: 425-430.

11 Wong TY, Chee SP. Risk factors of acute endophthalmitis after cataract extraction: a case control study in Asian eyes. Br J Ophthalmol 2004; 88: 29-31.

12 Kamalarajah S, Ling R, Silvestri G, Sharma NK, Cole MD, Cran G et al. Presumed infectious endophthalmitis following cataract surgery in UK: a case control study. Eye 2007; 21: 580-586.

13 Phillips 2nd, WB, Tasman WS. Postoperative endophthalmitis in association with diabetes mellitus. Ophthalmology 1994; 101: 508-518.

14 Zell K, Engelmann K, Bialasiewicz AA, Richard G. Endophthalmitis after cataract surgery: predisposing factors, infectious agents and therapy. Ophthalmologe 2000; 97: 257-263.

15 Montan PG, Koranyi G, Setterquist HE, Stridh A, Philipson BT, Wiklund K. Endophthalmitis after cataract surgery: risk factors relating to technique and events of the operation and patient history: a retrospective case-control study. Ophthalmology 1998; 105: 2171-2177.

16 Fernández-Rubio ME, Rebolledo-Lara L, Martinez-García M, Alarcón-Tomás M, Cortés-Valdés C. The conjunctival bacterial pattern of diabetics undergoing cataract surgery. Eye 2010; 24: 825-834.

17 Endophthalmitis vitrectomy study. Microbiologic factors and visual outcome in the endophthalmitis vitrectomy study. Am J Ophthalmol 1996; 122: 830-846.

18 Callegan MC, Engelbert M, Parke II DW, Jett BD, Gilmore MS. Bacterial endophthalmitis: Epidemiology, therapeutics, and bacterium-host interactions. Clin Microbiol Rev 2002; 15: 111-124.

19 Sadaka A, Durand ML, Gilmore MS. Bacterial endophthalmitis in the age of outpatients intravitreal therapies and cataract surgery: Host-microbe interations in intraocular infection. Prog Ret Eye Res 2012; 31: 316-331.

20 Scott IU, Loo RH, Flynn Jr, HW, Miller D. Endophthalmitis caused by Enterococcus faecalis: antibiotic selection and treatment outcomes. Ophthalmology 2003; 110: 1573-1577.

21 Miller JJ, Scott IU, Flynn Jr, HW, Smiddy WE, Corey RP, Miller D. Endophthalmitis caused by Streptococcus pneumoniae. Am J Ophthalmol 2004; 138: 231-236.

22 Chen KJ, Lai CC, Sun MH, Chen TL, Yang KJ, Kuo YH et al. Postcataract endophthalmitis caused by Enterococcus faecalis. Ocul Immunol Inflamm 2009; 17: 364-369.

23 Major JC, Engelberg M, Flynn HW, Miller D, Smiddy WD, Davis JL. Staphylococcus aureus endophthalmitis: antibiotic susceptibilities, methicillin resistance, and clinical outcome. Am J Ophthalmol 2010; 149: 278-283. 
24 Pijl BJ, Theelen T, Tilanus MAD, Rentenaar R, Crama N. Acute endophthalmitis after cataract surgery: 250 consecutive cases treated at a tertiary referral center in the Netherlands. Am J Ophthalmol 2010; 149: 482-487.

25 Cornut PL, Thuret G, Creuzot-Garcher C, Maurin M, Pechinot A, Bron A et al. Relationship between baseline clinical data and microbiologic spectrum in 100 patients with acute postcataract endophthalmitis. Retina 2012; 32: 549-557.

26 Speaker MG, Milch FA, Shah MK, Eisner W, Kreiswirth BN Role of external bacterial flora in the pathogenesis of acute postoperative endophthalmitis. Ophthalmology 1991; 98: 639-649.

27 Fahmy JA, Moller S, Bentzon MW. Bacterial flora in relation to cataract extraction. I. Material, methods and preoperative flora. Acta Ophthalmol (Copenh) 1975; 53: 458-475.

28 Rubio EF. Influence of age on conjunctival bacteria of patients undergoing cataract surgery. Eye 2006; 20: 447-454

29 Miño De, Kaspar H, Ta CN, Froehlich SJ, Schaller UC, Engelbert $\mathrm{M}$ et al. Prospective study of risk factors for conjunctival bacterial contamination in patients undergoing intraocular surgery. Eur J Ophthalmol 2009; 19: 717-722.

30 Suto C, Morinaga M, Yagi T, Tsuji C, Toshida H. Conjunctival sac bacterial flora isolated prior to cataract surgery. Infect Drug Resist 2012; 5: 37-41.

31 Miller B, Ellis PP. Conjunctival flora in patients receiving immunosuppressive drugs. Arch Ophthalmol 1977; 95: 2012-2014.

32 Bilen H, Ates O, Astam N, Uslu H, Akcay G, Baykal O. Conjunctival flora in patients with type 1 or type 2 diabetes mellitus. Adv Ther 2007; 24: 1028-1035.

33 Martins EN, Alvarenga LS, Höfling-Lima AL, Freitas D, Zorat-Yu MC, Farah ME et al. Aerobic bacterial conjunctival flora in diabetic patients. Cornea 2004; 23: 136-142.

34 Pennisi E. Microbial survey of human body reveals extensive variation. Science 2012; 336: 1369-1371.

35 Fernández-Rubio E, Urcelay JL, Cuesta-Rodriguez T. The antibiotic resistance pattern of conjunctival bacteria: a key for designing a cataract surgery prophylaxis. Eye 2009; 23: 1321-1328.

36 Department Health Human Services. The International Classification of Diseases, 9th revision. Clinical Modifications. ICD-9CM. 3rd ed. Department Health Human Services: Washington DC, USA, 1989

37 Desai P, Minassian DC, Reidy A. National cataract surgery survey 1997-8: a report of the results of the clinical outcomes. Br J Ophthalmol 1999; 83: 1336-1340.
38 Riley AF, Malik TY, Grupcheva CN, Fisk MJ, Craig JP, McGhee CN. The Auckland cataract study: comorbidity, surgical techniques, and clinical outcomes in a public hospital service. Br J Ophthalmol 2002; 86: 185-190.

39 Reeves SW, Tielsch JM, Katz J, Bass EB, Schein OD. A selfadministered health questionnaire for the preoperative risk stratification of patients undergoing cataract surgery. Am J Ophthalmol 2003; 135: 599-606.

40 Moore KL, Boscardin WJ, Steinman MA, Schwartz JB. Age and sex variation in prevalence of chronic medical conditions in older residents of U.S. nursing homes. J Am Geriatr Soc 2012; 60: 756-764.

$41 \mathrm{Xu}$ L, You QS, Wang YX, Jonas JB. Associations between gender, ocular parameters and diseases: the Beijing Eye study. Ophthalmic Res 2011; 45: 197-203.

42 Wu R, Wang JJ, Mitchell P, Lamoureux EL, Zheng Y, Rochtchina $\mathrm{E}$ et al. The Singapore malay eye study. Smoking, socioeconomic factors, and age-related cataract. Arch Ophthalmol 2010; 128: 1029-1035.

43 Fernández-Rubio ME, Cuesta-Rodríguez T, Urcelay-Segura JL, Cortés-Valdés C. Prospective study of risk factors for conjunctival bacterial contamination in patients undergoing intraocular surgery. Eur J Ophthalmol 2010; 20: 805-806.

44 Packer M, Chang DF, Dewey SH, Little BC, Mamalis N, Oetting TA et al. ASCRS Cataract Clinical Committee. Prevention, diagnosis, and management of acute postoperative bacterial endophthalmitis. J Cataract Refract Surg 2011; 37: 1699-1714.

45 Clark A, Morlet N, Ng JQ, Preen DB, Semmens JB. Whole population trends in complications of cataract surgery over 22 years in Western Australia. Ophthalmology 2011; 118: 1055-1061.

46 Stein JD, Grossman DS, Mundy KM, Sugar A, Sloan FA. Severe adverse events after cataract surgery among medicare beneficiaries. Ophthalmology 2011; 118: 1716-1723.

47 Fernandez-Rubio ME. Geographic location and endophthalmitis. Ophthalmology 2012; 119(2655-6): e1-e5.

48 Rubio EF. Climatic influence on conjunctival bacteria of patients undergoing cataract surgery. Eye 2004; 18: 778-784.

49 Dong Q, Brulc JM, Iovieno A, Bates B, Garoutte A, Miller D et al. Diversity of bacteria at healthy human conjunctiva. Invest Ophthalmol Vis Sci 2011; 52: 5408-5413.

50 Chiquet C, Cornut PL, Benito Y, Thuret G, Maurin M, Lafontaine $\mathrm{PO}$ et al. Eubacterial PCR for bacterial detection and identification in 100 acute postcataract surgery endophthalmitis. Invest Ophthalmol Vis Sci 2008; 49: 1971-1978.

Supplementary Information accompanies this paper on Eye website (http://www.nature.com/eye) 